\title{
CORRESPONDENCE
}

\section{REF.: PENICILLIN AT THE LATE STAGE OF LEPTOSPIROSIS: A RANDOMIZED CONTROLLED TRIAL}

July 25,2003

Dear Sir,

We read the article "Penicillin at the late stage of leptospirosis: a randomized controlled trial" with great interest ${ }^{1}$. They evaluated the effect of penicillin at the late stage of leptospirosis on mortality and concluded that the initiation of penicillin in patients with severe forms of leptospirosis after at least four days of symptomatic leptospirosis is not beneficial. However they did not described the sample size calculations which may affect the results. In addition multiple organ involvement and fulminant disease is usually associated with renal failure and/or thrombocytopenia in leptospirosis ${ }^{2-4}$. With regard to renal failure and thrombocytopenia only creatinine levels and bleeding were analyzed in the mentioned study. It would be interesting to know if there was any association between mortality and trombocytopenia and/or renal failure, also if is there any difference between the penicillin and control group regarding the presence of thrombocytopenia and renal failure. Also adjunctive therapies may affect the outcome of the disease. In renal failure adequate therapy can prevent irreversible renal damage. In a series of 36 patients with leptospirosis, 27 (65\%) of them had acute renal failure and $13(48 \%)$ needed renal replacement therapy such as haemodialysis. Antimicrobial therapy may not be the only factor which affect the outcome in leptospirosis.

Prof. Hakan Leblebicioglu, MD Dept. Infectious Diseases and Clinical Microbiology

Ondokuz Mayis University, Medical School Samsun, Turkey Fax: +90.362-4576029

E-mail: hakanomu@omu.edu.tr www.ann-clinmicrob.com

\section{REFERENCES}

1. COSTA, E.; LOPES, A.A.; SACRAMENTO, E. et al. - Penicillin at the late stage of leptospirosis: a randomized controlled trial. Rev. Inst. Med. trop. S. Paulo, 45: 141-145, 2003.

2. LEBLEBICIOGLU, H. \& SUNBUL, M. - Leptospirosis: diagnosis and treatment. Infect. Dis. Pract. Clinicians, 27: 171-174, 2003.

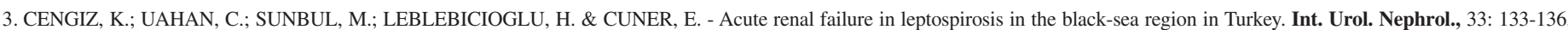
2002.

4. TURGUT, M.; SUNBUL, M.; BAYIRLI, D. et al. - Thrombocytopenia complicating the clinical course of leptospiral infection. J. int. med. Res., 30: 535-540, 2002. 